\title{
Mathematical model for determining rational machining conditions for flat grinding with the wheel periphery on machines with a rectangular table
}

\author{
Dmitriy L. Skuratov ${ }^{1}$, Dmitriy G. Fedorov ${ }^{1}$, and Dmitriy V. Evdokimov ${ }^{1, *}$ \\ ${ }^{1}$ Korolev Samara National Research University, Samara, Russia
}

\begin{abstract}
A mathematical model is presented for determining the rational machining conditions for flat grinding operations by the rim of a wheel on machines with a rectangular table consisting of a linear objective function and linear inequality constraints. As the objective function, the equation, determining the main machining time, was used. And constraints which are related to the functional parameters and parameters determining the machining quality and the kinematic capabilities of the machine were used as inequality constraints.
\end{abstract}

\section{Introduction}

The analysis of literary sources has shown, mathematical models that allow to determine rational machining conditions for round outer [5, 7] and internal [5] grinding. With respect to the process of flat grinding, the relationships connecting the parameters of the mode of flat grinding with parameters of the surface roughness are known and were given, for example, in [6], which allows, based on the required surface roughness, to determine the parameters of the cutting mode.

In this paper, a mathematical model designed to determine the rational machining conditions for flat grinding operations with the wheel periphery on ma-chines with a rectangular cross table and including a linear objective function and linear inequality constraints was presented. In this model, the machine processing time is chosen as the objective function, and the constraint associated with the tool life of the wheel, as well as constraints related both to the functional parameters of the cutting process (effective power, temperature), and to the parameters defining quality of processing (accuracy, surface roughness) and kinematic capabilities of the machine were used as constraints-inequalities.

\section{Selection of objective function and technical limitations}

The cutting modes, calculated with the use of economic periods of tool life and ensuring the shortest possible formation time, will be simultaneously and the most economical. There-

\footnotetext{
${ }^{*}$ Corresponding author: dmitry.evd.ssau@gmail.com
} 
fore, as an objective function for flat grinding, taking into account the recommendations given in paper [5], it is expedient to use the equation determining the main (machine) processing time and it has the form:

$$
t_{p}=\frac{1,1 L_{g} B_{g} \Delta}{1000 v_{d} S_{x} S_{t_{x}} q_{d}},
$$

where $L_{g}$ - the length of grinding or the overall length of the location of the polished surfaces on the machine table, $\mathrm{mm} ; B_{g}$ - width of grinding or overall width of the location of the polished surfaces on the machine table, $\mathrm{mm} ; \Delta$ - tolerance for grinding to the side; $v_{d}-$ speed (longitudinal) of the grinding machine table, $\mathrm{m} / \mathrm{min}$; $\mathrm{Sx}$ is the transverse feed per one table move, mm/stroke; $S_{t_{x}}$ - feed to depth by one table move, $\mathrm{mm} /$ stroke; $q_{d}$ - the number of simultaneously machined parts, pcs.

\subsection{Constraint associated with the tool life of the grinding wheel}

The improved formula for determining the tool life of the grinding wheel has been transformed to:

$$
T_{k}=\frac{0,35}{\left(v_{d} S_{d} S_{t_{x}}\right)^{2}} k_{1}^{T} k_{2}^{T} k_{3}^{T}
$$

where $T_{k}$ is the tool life of the grinding wheel, min; $k_{1}^{T}$ - coefficient, taking into account influence of physical and mechanical properties of the group of steels and alloys, to which the machined material is related, for the tool life of the wheel; $k_{2}^{T}, k_{3}^{T}$ - coefficients that take into account, respectively, influence of the geometric dimensions and the wheel design of the wheel for its tool life.

In this case the formula (2) and the solution relatively to $v_{d} S_{x} S_{t_{x}}$, has the form:

$$
v_{d}^{2}\left(10 S_{x}\right)^{2}\left(1000 S_{t_{x}}\right)^{2} \leq \frac{0,35 \cdot 10^{8} B_{w}^{2}}{T_{k}} k_{1}^{T} k_{2}^{T} k_{3}^{T} .
$$

In inequality (3) and subsequent technical constraints, for convenience of calculations, it has been accepted that instead of $S_{x} \rightarrow 10 S_{x}$, instead of $S_{t_{x}} \rightarrow 1000 S_{t_{x}}$, with the corresponding corrections on the right-hand side.

\subsection{Constraint related to the power of the machine}

When flat grinding, it is necessary that the effective power $N_{e f}$, which is spent to the cutting process, does not exceed the power which is supplied to the spindle of the flat grinding machine. It means that:

$$
N_{e f} \leq N_{s p}
$$

where $N_{e f}$ is the effective cutting power, $\mathrm{kW} ; N_{s p}$ - power, driven to the spindle of the flat grinding machine, $\mathrm{kW}$. 
To determine the effective power in the case of flat grinding with the wheel periphery on a machine with a rectangular table, the formula given in $[4,5]$ was taken as a basis. In a detailed form, this formula can be represented as

$$
N_{e f}=0,63\left(v_{d} S_{x} S_{t_{x}}\right)^{0,7} B_{w}^{0,25} k_{1}^{N} k_{2}^{N} k_{3}^{N},
$$

where $k_{1}^{N}, k_{2}^{N}, k_{3}^{N}$ - the correction coefficients that take into account influence of change in the hardness of the grinding wheel, the physical and mechanical properties of the group of steels and alloys to which the material is related, and the design of the wheel for effective power.

If transfer the formula (5) into (4) and, after the transformation and the solution relatively to the second technical constraint, it has become possible to obtain the following form:

$$
v_{d}^{0,7}\left(10 S_{x}\right)^{0,7}\left(1000 S_{t_{x}}\right)^{0,7} \leq \frac{10^{2,8} \cdot N_{e n . \mathrm{sp}} \eta}{0,63 B_{w}^{0,25} k_{1}^{N} k_{2}^{N} k_{3}^{N}},
$$

where $N_{e n \text {.sp }}$ - power of the spindle motor of the flat grinding machine, $\mathrm{kW} ; \eta$ - The efficiency of the kinematic chain of the main movement mechanism.

\subsection{Constraint associated with the average contact temperature of grinding.}

When grinding a significant amount of heat is released, this is a result of high cutting speeds. An analysis of the results of the investigations which are presented in $[3,7$, etc.] shows that the state of the surface layer of the polished parts is determined not only by the average contact temperature that occurred during machining, but by all space-time temperature field.

Proceeding from the foregoing, the condition must be valid:

$$
\theta_{\max } \leq \theta_{c r},
$$

where $\theta_{\max }$ and $\theta_{c r}$ are respectively the maximum average contact and critical temperatures in the cutting zone, ${ }^{\circ} \mathrm{C}$.

The maximum average contact temperature can be determined from formula

$$
\theta_{\max }=\theta_{0}+\Delta \theta_{\max },
$$

where $\theta_{0}$ is the initial temperature of the workpiece surface, ${ }^{\circ} \mathrm{C}$.

If transfer the formula (8) into (7), it has become possible to obtain a technical constraint connected with the grinding temperature:

$$
\Delta \theta_{\max } \leq \theta_{c r}-\theta_{0}
$$

The maximum increment of the temperature of the workpiece surface in the contact zone is determined by the formula given in the work of V.A. Sipailov. [3], which has the form:

$$
\Delta \theta_{\max }=\frac{2 q}{\lambda} \sqrt{\frac{a L_{k}}{\pi v_{d}}}
$$


where $q$ - heat flow rate, $\mathrm{W} / \mathrm{m}^{2} ; \lambda$ - coefficient of heat conductivity, $\mathrm{W} /(\mathrm{m} \cdot \mathrm{K}) ; a$ - coefficient of thermal diffusivity, $\mathrm{m}^{2} / \mathrm{s} ; L_{k}$ - the arc length of the wheel contact with the workpiece, $\mathrm{m} ; v_{d}$ - speed (longitudinal) of the grinding machine table, $\mathrm{m} / \mathrm{s}$.

The heat flow rate during the grinding of the workpieces, in particular the flat grinding with the wheel periphery, can be determined by the following formula:

$$
q=\frac{N_{e f}}{F_{k}} k_{Q}=\frac{N_{e f}}{L_{k} \cdot B_{k}} k_{Q},
$$

where $q$ - heat flow rate, $\mathrm{W} / \mathrm{m}^{2} ; N_{e f}$ - effective power, $\mathrm{W} ; F_{k}$ - area of contact of the wheel with the workpiece, $\mathrm{m}^{2} ; L_{k}$ - length of the arc of contact between the circle and the workpiece, $\mathrm{m} ; B_{w}$ - height of grinding wheel, $\mathrm{m} ; k_{Q}-\mathrm{a}$ coefficient that indicates how much of the heat power, released during grinding, entered to the workpiece.

$$
\Delta \theta=\frac{5,508 \cdot 10^{7,5} v_{d}^{0,2} S_{x}^{0,7} S_{t_{x}}^{0,7} a^{0,5} k_{Q} k_{1}^{N} k_{2}^{N} k_{3}^{\theta}}{\lambda B_{w}^{0,75} D_{k}^{0,25}}
$$

If transfer the formula (12) into (9) and, after the transformation and the solution with relative to $v_{\partial} S_{x} S_{t_{x}}$ it will be possible to obtain the third technical constraint:

$$
v_{d}^{0,2}\left(10 S_{x}\right)^{0,7}\left(1000 S_{t_{x}}\right)^{0,45} \leq \frac{0,1816 \cdot 10^{-5,45} \lambda B_{w}^{0,75} D_{k}^{0,25}\left(\theta_{c r}-\theta_{0}\right)}{a^{0,5} K_{Q} K_{1}^{N} K_{2}^{N} K_{3}^{\theta}} .
$$

\subsection{The constraint associated with precision of machining}

When it is needed to machine a workpiece surface with an error which does not exceed the tolerance for the resulting size, it is possible to use the dependence presented in [2]:

$$
S_{t_{x}}=C_{S} \frac{D_{k} \Delta^{0,32}}{v_{d} S_{x} T^{0,75}} K_{H} K_{B} K_{l} K_{D} K_{\delta} K_{M},
$$

where $C_{S}$ is the coefficient for feed determining; $\Delta$ - allowance for machining during grinding, mm; $K_{H}$ - coefficient that takes into account the thickness of the workpiece; $K_{B}$ - coefficient that takes into account the width of the workpiece; $K_{l}$-coefficient that takes into account the length of the workpiece; $K_{D}$ - coefficient that takes into account the diameter of the grinding wheel; $K_{\delta}$ - coefficient that takes into account the accuracy (grade of accuracy) of the machining; $K_{M}$ - coefficient that takes into account the group of steels and alloys to which the polished material relates.

After solving the relationship (14) with relative to $v_{d} S_{x} S_{t_{x}}$, the fourth technical con-

straint:

$$
v_{d}\left(10 S_{x}\right)\left(1000 S_{t_{x}}\right) \leq \frac{C_{S} D_{k} \Delta^{0,32} \cdot 10^{4}}{T^{0,75}} K_{H} K_{B} K_{l} K_{D} K_{\delta} K_{M} .
$$




\subsection{Constraint, related to the maximum permissible roughness of the polished surface}

In the case of flat grinding with the wheel periphery, the average arithmetic deviation of the surface profile can be determined from the formula given in paper [5] and adapted to the process of flat grinding

$$
R a=C_{R a}\left(\frac{v_{d}}{60 v_{k}}\right)^{0,5}\left(\frac{S_{t_{x}}}{D_{k}}\right)^{0,25}\left(\frac{S_{x}}{B_{w}}\right)^{0,5} k_{g e n}^{0,5} k_{R a} d_{g r}^{0,5} n^{m_{R a}},
$$

where $R a$ is the arithmetic average deviation of the profile, $\mu \mathrm{m} ; C_{R a}, m_{R a}-$ coefficient and index, depending on the group to which the processed material belongs; $D_{\kappa}-$ wheel diameter which is used for grinding, $\mathrm{mm} ; k_{\text {gen }}$ - coefficient taking into account the influence of the grade of abrasive material, surface porosity [1] and the structure of the wheel, as well as the conditions for its dressing on the formation of surface roughness; $k_{R a}$ - coefficient that takes into account the influence of the design of the wheel on the surface roughness; $d_{g r}$ - grain size, $\mathrm{mm} ; n$ - number of strokes of sparking-out.

After simple transfer and evaluating of the equation (16) with relative to $v_{d} S_{x} S_{t_{x}}$ the fifth technical constraint will obtain the following form:

$$
v_{d}^{0,5}\left(10 S_{x}\right)^{0,5}\left(1000 S_{t_{x}}\right)^{0,25} \leq \frac{R a\left(60 \cdot 10 v_{k} B_{w}\right)^{0,5}\left(1000 D_{k}\right)^{0,25}}{C_{R a}\left(k_{g e n} d_{g r}\right)^{0,5} k_{R a} n^{m_{R a}}} .
$$

\subsection{Constraint related to the kinematic capabilities of the machine}

The technical constraints due to the kinematic capabilities of the machine have the forms: $v_{d} \geq v_{d . m \min }, v_{d} \leq v_{d . m \text { max }}, 10 S_{x} \geq 10 S_{x \mathrm{~m} \min }, 10 S_{x} \leq 10 S_{x \mathrm{~m} \max }, 1000 S_{t_{x}} \geq 1000 S_{t_{x} \mathrm{~m} \min }$,

$$
1000 S_{t_{x}} \leq 1000 S_{t_{x} \mathrm{~m} \max }
$$

where $v_{d . m \min }, v_{d . m \text { max }}$ - the minimum and maximum speed of movement of the machine table, $\mathrm{m} / \mathrm{min} ; S_{x \mathrm{~m} \min } S_{x \mathrm{~m} \max }$ - the minimum and maximum transverse feed of the machine, mm/stroke; $S_{t_{x} \mathrm{~m} \min } S_{t_{x} \mathrm{~m} \max }$ - the minimum and maximum feed to the depth of the machine, $\mathrm{mm} / \mathrm{stroke}$.

\section{The development of a mathematical model}

To obtain a system of linear inequality constraints and a linear objective function simulating the process of flat grinding with the wheel periphery on machines with a rectangular table, it is necessary to take logarithm of dependancy (3), (6), (13), (15), (17-18), which after the usage of the symbols within it, the relations have got the form 


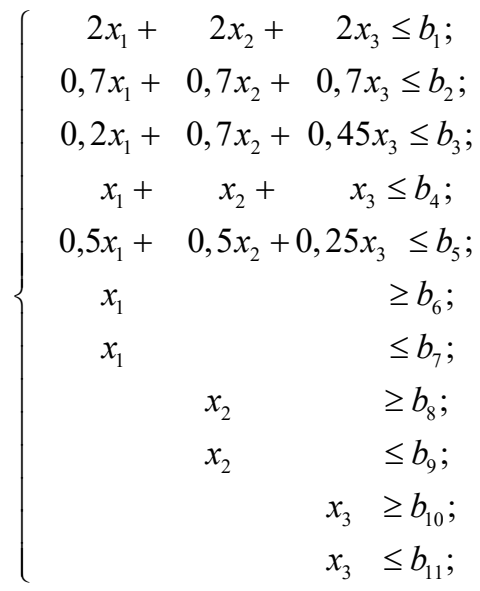

$$
\begin{aligned}
& f_{0}=c_{0}-x_{1}-x_{2}-x_{3},
\end{aligned}
$$

where $x_{1}=\ln v_{d} ; x_{2}=\ln \left(10 S_{x}\right) ; x_{3}=\ln \left(1000 S_{t_{x}}\right) ; b_{1}=\ln \frac{0,35 \cdot 10^{8} B_{w}^{2}}{T_{k}} k_{1}^{T} k_{2}^{T} k_{3}^{T} ;$

$$
\begin{gathered}
b_{2}=\ln \frac{10^{2,8} \cdot N_{e n . \mathrm{sp}} \eta}{0,63 B_{w}^{0,25} k_{1}^{N} k_{2}^{N} k_{3}^{N}} ; \quad b_{3}=\ln \frac{0,1816 \cdot 10^{-5,45} \lambda B_{w}^{0,75} D_{k}^{0,25}\left(\theta_{c r}-\theta_{0}\right)}{a^{0,5} K_{Q} K_{1}^{N} K_{2}^{N} K_{3}^{\theta}} ; \\
b_{4}=\ln \frac{C_{S} D_{k} \Delta^{0,32} \cdot 10^{4}}{T^{0,75}} K_{H} K_{B} K_{l} K_{D} K_{\delta} K_{M} ; b_{5}=\ln \frac{R a\left(60 \cdot 10 v_{k} B_{w}\right)^{0,5}\left(1000 D_{k}\right)^{0,25}}{C_{R a}\left(k_{g e n} d_{g r}\right)^{0,5} k_{R a} n^{m_{R a}}} ; \\
b_{6}=\ln v_{d . m \text { min }} ; b_{7}=\ln v_{d . m \text { max }} ; b_{8}=\ln \left(10 S_{x \mathrm{~m} \min }\right) ; b_{9}=\ln \left(10 S_{x \mathrm{~m} \max }\right) ; \\
b_{10}=\ln \left(1000 S_{t_{x} \mathrm{~m} \min }\right) ; b_{11}=\ln \left(1000 S_{t_{x} \mathrm{~m} \max }\right) ; f_{0}=\ln t_{0} ; c_{0}=\ln \frac{11 \cdot L_{g} B_{g} \Delta}{q_{d}}
\end{gathered}
$$

The solution of the problem can be substantially simplified by reducing of the system (19) To carry out the transformations, it is necessary to express $x_{1}$ from the limitationinequality related to the grinding temperature:

$$
x_{1}=5 b_{3}-3,5 x_{2}-2,25 x_{3}
$$

As a result, the new system containing two unknowns $x_{2}$ and $x_{3}$ has been obtained: 


$$
\begin{aligned}
& \left\{\begin{array}{rrr}
-5 x_{2}-2,5 x_{3} & \leq b_{1}-10 b_{3} \\
-1,75 x_{2}-0,875 x_{3} & \leq b_{2}-3,5 b_{3} \\
-2,5 x_{2} & -1,25 x_{3} & \leq b_{4}-5 b_{3} \\
-1,25 x_{2}-0,875 x_{3} & \leq b_{5}-2,5 b_{3} \\
-3,5 x_{2}-2,25 x_{3} & \geq b_{6}-5 b_{3} \\
-3,5 x_{2}-2,25 x_{3} & \leq b_{7}-5 b_{3} \\
x_{2} & \geq b_{8} \\
x_{2} & \leq b_{9} \\
x_{3} & \geq b_{10} \\
x_{3} & \leq b_{11}
\end{array}\right. \\
& f_{0}=c_{0}-5 b_{3}+2,5 x_{2}+1,25 x_{3} \text {. }
\end{aligned}
$$

Since at this particular problem, $c_{0}-5 b_{5}$ is a constant value, the function $f_{0}$ reaches its minimum value if $x_{2}$ and $x_{3}$ unknowns take minimal values which must be corresponded to the constraint system (20).

\section{Conclusion}

1. Based on the analysis and generalization of the literature data, as well as the authors' own research, the objective function was determined and technical con-straints were obtained for the operation of flat grinding with the wheel periphery on machines with a rectangular table.

2. A mathematical model has been developed for determining the rational cut-ting conditions (design and tool characteristics, cutting modes, coolant, etc.) on the operations of flat grinding with the wheel periphery.

\section{References}

1. Ostrovskij, V.I. Teoreticheskie osnovy processa shlifovaniya (L.: Izd-vo Leningr. unta, 1981)

2. V.I. Baranchikov, A.V. ZHarinov, N.D. YUdina i dr.; pod obshch. red. V.I. Baranchikova, Progressivnye rezhushchie instrumenty $i$ rezhimy rezaniya metallov: spravochnik (M.: Mashinostroenie, 1990.)

3. Sipajlov, V.A. Teplovye processy pri shlifovanii i upravlenie kachestvom poverhnosti (M.: Mashinostroenie, 1978)

4. D.L. Skuratov, V.N. Trusov, YU.A., Issledovanie vnutrennego kruglogo shlifovaniya zharo-prochnoj stali EP517-SH abrazivnymi krugami s preryvistoj rabochej poverhnost'yu, Progressivnye instrumenty i metody obrabotki rezaniem aviacionnyh materialov: mezhvuz. sb. nauch. tr. , Kujbyshev, 1989, p. 20-25.

5. D.L. Skuratov, V.N. Trusov. Opredelenie racional'nyh uslovij obrabotki pri proizvodstve detalej GTD (Samara: Samar. nauch. centr RAN, 2002)

6. Suslov, A.G. Kachestvo poverhnostnogo sloya detalej mashin ( M.: Mashinostroenie, 2000)

7. P.I. Yashchericyn, A.K. Cokur, M.L., Eremenko Teplovye yavleniya pri shlifovanii i svojstva obrabotannyh poverhnostej (Minsk: Nauka i tekhnika, 1973) 